\title{
The Walter/Palya experiment controller users' group meeting and help session
}

\author{
DONALD E. WALTER \\ Jacksonville State University, Jacksonville, Alabama
}

This is a report of the group meeting for users of the Walter/Palya ECBASIC experiment controller. Several questions of broad interest were raised and answered. Possibilities for the future were discussed.

During the interactive group meeting for users of the Walter/Palya experiment controller, there were a number of questions concerning the capabilities of the experiment control board (ECB) and its ECBASIC interpreter.

1. What is the input measuring accuracy and input measuring speed of ECBASIC, and how can it be improved?

ECBASIC was not designed to measure reaction time (RT) or interresponse times (IRTs). It can be used for such measurements, but unfortunately only in a cumbersome manner, and results are accurate only to tens of milliseconds. ECBASIC was designed to count inputs over a sample period of time.

ECBASIC has an interrupt routine that interrupts program execution every $10 \mathrm{msec}$ and snapshots the state of the eight inputs. ECBASIC recognizes a switch opening as an input only if that switch has been off (closed) for the three preceding interrupt scans. Otherwise, the switch opening is presumed to be contact bounce. If a switch opening is determined to be an input, the variable associated with that input (with the COUNT statement in the user program) is incremented within about $.1 \mathrm{msec}$. As a result, the average time lag to the incrementation of the variable associated with an input is $5.1 \mathrm{msec}$; however, the lag could be anywhere between 1 and $10 \mathrm{msec}$. It should be noted that the debounce procedure limits responding to once every $40 \mathrm{msec}$.

An additional factor in measuring the fine temporal grain of responding is the execution time of ECBASIC statements. Currently, ECBASIC stores its program in ASCII and must interpret each statement as it goes. As a result, execution is rather slow. A typical instruction takes 4 to $5 \mathrm{msec}$ to execute. Because the access of a user program to the occurrence of a response is only through the incrementation of its assigned variable, measurement of the time between consecutive inputs requires that the user program wait for that variable to increment, record the time, wait for the variable to change again, and then record the time again (or calculate a difference time). At

Requests for reprints should be sent to the author, c/o W. L. Palya, Department of Psychology, Jacksonville State University, Jacksonville, AL 36265 best, a clever programmer can expect to do this in 20 to $30 \mathrm{msec}$. For other than IRT or RT analysis, this would not be a problem, but for these applications it may be too slow.

There are two ways ECBASIC can be patched to provide RT or IRT data. First, interrupts can be set to occur more often than every $10 \mathrm{msec}$ and only one or two inputs checked for bouncing. In this case, the scan interrupt can be set to as low as $1 \mathrm{msec}$. However, the interrupt overhead for inputs is $274 \mu \mathrm{sec}$ plus $92 \mu \mathrm{sec}$ for each active input (connected via the COUNT instruction). The cost of this would be to increase the percentage of overhead from $5 \%$ to $50 \%$. (A factor of 10 increase in speed results in a factor of 10 increase in overhead.)

A second solution would be to add a new function to ECBASIC, specifically to designate certain inputs as RT measuring inputs and to return millisecond timing information instead of input counts. Unfortunately, this would add a substantial amount of overhead, slowing down the execution of all ECBASIC instructions.

The most satisfactory solution is to completely rewrite the ECBASIC interpreter to make these kinds of measurements possible in a general environment. Instruction pretokenization to speed scanning and recognition time could easily speed up execution by a factor of 10 . The ability to provide finer RT data is a high-priority enhancement. If you have a PDP-11 or a software technician, an immediate solution is to look into the ECL control language (Walter \& Palya, 1985). The ECL provides 1-msec accuracy.

2. Some spreadsheets expect foreign input data to have tabs (ASCII 09) between data items. How can I get ECBASIC to output tabs?

Simply print the tab as a character inside a quoted string on your print line. For example, type

$$
40 \text { PRINT A1;“"I";A2 }
$$

where ${ }^{-} I$ is the tab character. Care must be taken that the editor on your host machine does not automatically convert tabs into spaces. If the tab character is in the ASCII file sent to the ECBASIC controller, the tab will be printed in the output. 
3. When written in ECBASIC, a select-withoutreplacement is much too slow to be usable. Can a selectwithout-replacement be added to the ECBASIC instruction set?

The ability to select a random element from a set of elements and then remove that element from the set can be added to ECBASIC. Depending on my professional commitments, the additional function may be available as early as January $1988 .{ }^{1}$ I will add it as soon as I can. In the meantime, the easiest work-around method is to fill an array with a randomly arranged sequence of the desired elements during reinforcement or some other dead time. Then sequentially draw the elements out of the array.

\section{Are there any problems that may be encountered} by an inexperienced person building experiment control boards?

No! Although it is not a do-it-yourself kit, the ECB can and has been assembled by people who had never used a soldering iron before. The manual (Walter \& Palya, 1985 ) has a good set of guidelines for building ECBs that are based on the experiences of a number of people who have built them. The most important thing is to be careful and do not rush. A good temperature-controlled soldering iron is helpful if you are making a number of boards.

The ECB has actually gone through several revisions. When construction problems were detected at other facilities, the etch revision was altered to eliminate them.

Some problems have occurred that are attributable to people's not looking through the manual. I am sympathetic with people's cynicism about the usability of manuals; however, a great deal of effort has been put into the experiment controller manual to make it complete and comprehensible. The manual describes how to construct ECBs, where to buy parts, how to configure the board, how to set up true networking, what each instruction does, and how to use the ECB. Example programs are included. The manual also covers information of interest only to hackers, but those sections are generally separated from the information for general users. In fact, the index will probably work for you. An attempt was made to provide step-by-step instructions for setting up a working system. If you have a problem, look through the manual for about $5 \mathrm{~min}$; if the solution does not become apparent by that time, do not hesitate to call. The manual may not have adequately dealt with your problem.

\section{What revisions in the hardware and/or software} are planned?

I cannot make any commitments, but we have considered a number of possible paths. Perhaps the board can be made less expensive by taking advantage of newer chips. We may add additional functionality, such as ana$\log$ I/O or CRT control. A compiled version of ECBASIC or a structured language may be developed. The problem with a compiled language, however, is the difficulty of supporting a wide variety of host computers. In this regard, we have considered supporting only the Macintosh and the IBM PC. Part of the purpose of this users' group meeting was to enable us to determine those capabilities most helpful to users. We would therefore like to solicit a wish list (or an "unwish" list) of enhancements so that our efforts to produce functionality are well spent.

\section{REFERENCE}

Walter, D. E., \& Palya, W. L. (1985). Document set for experiment controller. Jacksonville, AL: Jacksonville State University, Department of Psychology.

\section{NOTE}

1. SELECT has now been implemented and is included with all new PROM sets (Revision 1.34 and higher). Current users can obtain an upgrade by sending PROMs to William L. Palya, Department of Psychology, Jacksonville State University, Jacksonville, AL 36265. 